\title{
Varicella-zoster virus seroprevalence in children and adolescents in the pre- varicella vaccine era, Germany
}

Miriam Wiese-Posselt ${ }^{{ }^{*}}$ (D), Anette Siedler ${ }^{1}$, Annette Mankertz ${ }^{2}$, Andreas Sauerbrei ${ }^{3}$, Hartmut Hengel ${ }^{4}$,

Ole Wichmann ${ }^{1}$ and Christina Poethko-Müller ${ }^{5}$

\begin{abstract}
Background: In 2004, universal childhood varicella vaccination was introduced in Germany. We aimed to determine the age-specific prevalence of anti-varicella zoster virus (VZV) IgG-antibodies among children in the pre-varicella vaccine era in Germany, to identify factors associated with VZV seropositivity, and to assess the suitability of a commercially available ELISA for VZV seroepidemiological studies by comparing it with an in-house fluorescent antibody to membrane antigen test (FAMA) as the gold standard.
\end{abstract}

Methods: Serum samples of 13,433 children and adolescents aged 1-17 years included in the population-based German Health Interview and Examination Survey for Children and Adolescents (KiGGS; conducted 2003-2006) were tested for anti-VZV IgG by ELISA. All samples with equivocal ELISA results and a random selection of ELISAnegative and -positive samples were tested by FAMA. Statistical analyses were conducted using a weighting factor adjusting the study population to the total population in Germany. Seroprevalences were calculated as percentages (\%) with a 95\% confidence interval $(\mathrm{Cl})$. Odds ratios (OR) were computed by multivariate logistic regression to determine the association between socio-demographic factors and VZV seropositivity.

Results: The VZV seropositivity rate was $80.3 \%$ (95\% Cl: 79.3-81.3) in varicella-unvaccinated children and adolescents. VZV seropositivity rates differed significantly between age groups up to age 6 years, but not by gender. Of 118 retested serum samples with an equivocal ELISA result, $45.8 \%$ were FAMA-positive. The proportion of samples tested as falsenegative in by ELISA varied by age group: $2.6 \%$ in children aged $1-6$ and $9 \%$ in children aged $7-17$ years. Multivariate analyses showed that age, having older siblings, and early daycare start were associated with seropositivity in preschoolers; migration background reduced the chance of VZV seropositivity in schoolchildren (OR: 0.65; 0.43-0.99) and adolescents (OR: 0.62; 0.4-0.97).

Conclusion: In the pre-varicella vaccine era, most children in Germany contracted varicella by age six. Schoolchildren with a migration background and children without siblings have an increased risk of being VZV seronegative and should be targeted for catch-up vaccination, if they have no history of chickenpox. ELISAs are suitable for use in population-level serosurveys on VZV, but samples with equivocal ELISA results should be retested by FAMA.

Keywords: Varicella-zoster virus, Seroprevalence, Elisa, FAMA, Varicella vaccination

\footnotetext{
* Correspondence: Wiese-PosseltM@rki.de

${ }^{1}$ Department for Infectious Disease Epidemiology, Robert Koch Institute,

Immunization Unit, Seestrasse 10, 13353 Berlin, Germany

Full list of author information is available at the end of the article
}

(c) The Author(s). 2017 Open Access This article is distributed under the terms of the Creative Commons Attribution 4.0 International License (http://creativecommons.org/licenses/by/4.0/), which permits unrestricted use, distribution, and reproduction in any medium, provided you give appropriate credit to the original author(s) and the source, provide a link to the Creative Commons license, and indicate if changes were made. The Creative Commons Public Domain Dedication waiver (http://creativecommons.org/publicdomain/zero/1.0/) applies to the data made available in this article, unless otherwise stated. 


\section{Background}

Varicella-zoster virus (VZV) is a ubiquitous human herpesvirus. Primary infection with VZV results in varicella (chickenpox), which mostly affects children and is regarded as a generally benign illness [1]. However, varicella can also lead to serious complications resulting in hospitalization or even death [2]. Particularly in adults or in immunocompromised patients, varicella can take a severe course. After primary infection, immunity against varicella is considered to protect life-long. However, VZV becomes latent in the dorsal root ganglia; and later in life, VZV reactivation can cause herpes zoster (shingles).

In 2004, the German Standing Committee on Vaccination (STIKO) recommended universal varicella vaccination for children with a single dose to be given at the age of 11-14 months [3]. In 2009, a two-dose schedule was endorsed with a second dose at the age of 15-23 months [4]. In the birth cohorts of 2004 to 2009 , varicella vaccination coverage increased in 24-month-old children from $43 \%$ to $87 \%$ for the first dose and from $1 \%$ to $64 \%$ for the second dose [5]. With the increase in coverage, a significant decrease in varicella cases was observed in a nationwide physician-based sentinel surveillance system: from April 2005 to March 2012, an 85\% decline in varicella cases was reported by sentinel physicians. Furthermore, from April 2005 to March 2009, complications or severe courses of varicella declined by $81 \%[6,7]$. Based on sentinel and coverage data, vaccine effectiveness was estimated to be $87 \%$ after one vaccine dose and $97 \%$ after two vaccine doses [8].

For the evaluation of the current universal varicella vaccination strategy, disease burden data before and after vaccine introduction as well as data on vaccination uptake are essential [9]. Seroepidemiological data before and after vaccine introduction serve as an additional pillar in the evaluation of the vaccination strategy and can guide recommendations on catch-up vaccination activities. Although enzyme-linked immunosorbent assays (ELISAs) are the most commonly used test for measuring immunity against VZV (antiVZV IgG antibody levels), the fluorescent antibody to membrane antigen test (FAMA) is considered to be the "gold standard" assay for determining immunity against VZV, however, FAMA is more labor-intensive and time-consuming [10]. Studies directly comparing these two test methods are rare.

The objectives of this study were: (1) to representatively describe the age-specific prevalence of anti-VZV IgG antibodies for children and adolescents in Germany (1-17 years of age) in the pre-varicella vaccine era, (2) to identify social factors that are associated with the acquisition of anti-VZV IgG antibodies by naturally acquired varicella, and (3) to compare the commercially available standard ELISA versus an in-house FAMA with respect to its suitability as a test for use in population-level serosurveys.

\section{Methods \\ Study population}

From May 2003 to May 2006, the Robert Koch Institute conducted the German Health Interview and Examination Survey for Children and Adolescents (KiGGS), which was designed as a population-based, nationally representative cross-sectional study with 17,641 participants (8985 boys and 8656 girls). One participant withdrew the written consent, and thus 17,640 participants were included in KiGGS. The sampling methods used in this survey have been described elsewhere [11]. In addition to interviews with all parents and children ( $\geq 11$ years old) on demographics, socialization, and health topics, the vaccination status of each child was documented, and a physical examination of each child was performed. Furthermore, blood and urine samples were collected in 1- to 17-year-old children. Serum samples were stored at $-20{ }^{\circ} \mathrm{C}$ and subsequently tested for antibodies against various pathogens. The KiGGS survey was approved by the Federal Office for Data Protection and by the ethics committee of Charité University Medicine, Berlin, Germany.

\section{Serological testing}

In 2012 and 2013, 13,433 serum samples were tested for anti-VZV IgG by ELISA. Children vaccinated at least once against varicella were included in the analysis for the overall seroprevalence, but the analysis was stratified by vaccination status in order to allow an assessment of the pre-varicella vaccine era data. In a second step, samples that presented equivocal anti-VZV IgG results when tested by ELISA were retested by FAMA. Samples that presented anti-VZV IgG-negative results in children $\geq 6$ years of age were also retested by FAMA. For children $<6$ years of age, we selected a random subset of sera to be tested by FAMA since the proportion of children who were anti-VZV IgG-negative in this age group was expected to be much higher. The analysis of the first 1000 serum samples tested by ELISA already indicated that younger children have a lower antibody prevalence, which increased to above $80 \%$ in children aged 6 years and older. Furthermore, we also used FAMA to test 197 randomly selected serum samples that had shown a positive result in standard ELISA testing.

\section{Enzyme-linked immunosorbent assay (ELISA)}

The presence of anti-VZV IgG antibodies in each sample was determined using the EUROIMMUN Anti-VZV (IgG) ELISA kit and the EUROIMMUN Analyzer I-2P (Lübeck, Germany). According to the manufacturer's information, anti-VZV IgG concentrations of $\geq 110 \mathrm{IU} / \mathrm{l}$, 
$\geq 80$ to $<110 \mathrm{IU} / \mathrm{l}$, and $<80 \mathrm{IU} / \mathrm{l}$ were classed as positive, equivocal, and negative results, respectively [12]. The ELISA tests were performed by the National Reference Center Measles, Mumps, Rubella, which is located at the Robert Koch Institute, Berlin, Germany.

\section{Fluorescent antibody to membrane antigen test (FAMA)}

In our study, FAMAs were conducted using an in-house modification of the standard version described elsewhere [13]. VZV immunity was determined by measuring the level of fluorescent anti-human IgG that was bound to VZV IgG antibodies linked to viral envelope glycoproteins on the surface of VZV-infected fibroblasts. Serum samples with FAMA titers of $\geq 1: 2$ were considered as positive for immunity against VZV; in other words, these anti-VZV IgG sera levels correlate with protection against varicella infection. Detailed information on the in-house FAMA protocol used in this study has been described previously by Sauerbrei et al. [14]. The FAMAs were carried out at the German Consulting Laboratory for HSV and VZV, Jena University Hospital, FriedrichSchiller-University of Jena, Germany.

\section{Statistical analysis}

Analyses of epidemiological and laboratory data were performed using a weighting factor that adjusted the distribution of the study population from which a blood sample could be taken, according age group, sex, residence in the eastern or western part of Germany or in Berlin, and according nationality to match the distribution of these characteristics in the total population in Germany as of 31 December 2004 [11]. Weighted seroprevalence data are reported as percentages (\%) with a 95\% confidence interval (CI). ELISA data were stratified by age, gender, and varicella vaccination status. Significant differences between the gender and age groups were assumed if the $95 \%$ CIs did not overlap. The test qualities of ELISA and FAMA were compared descriptively on the basis of non-weighted seroprevalence data. For risk factor analyses, VZV seropositivity functioned as the dependent variable and was defined as a positive ELISA result, or as a positive FAMA result in cases when the ELISA had shown an equivocal result. The weighted data set was used. Multivariate logistic regression analyses for complex samples were used to determine possible factors associated with VZV seropositivity (inclusion of variables was guided by hypotheses: age, gender, older and younger siblings living in the same household, migration status, social economic status (SES) and age at start of day-care attendance). The social status score was computed based on three components: parents' educational and professional statuses as well as the total income available to the family household [15]. Analyses were performed with SPSS version 20 (SPSS Inc., Chicago, Illinios, USA).

\section{Results}

Of the 17,640 KiGGS participants, 13,433 children and adolescents that were $1-17$ years of age were included in the VZV seroprevalence study. Of those excluded from

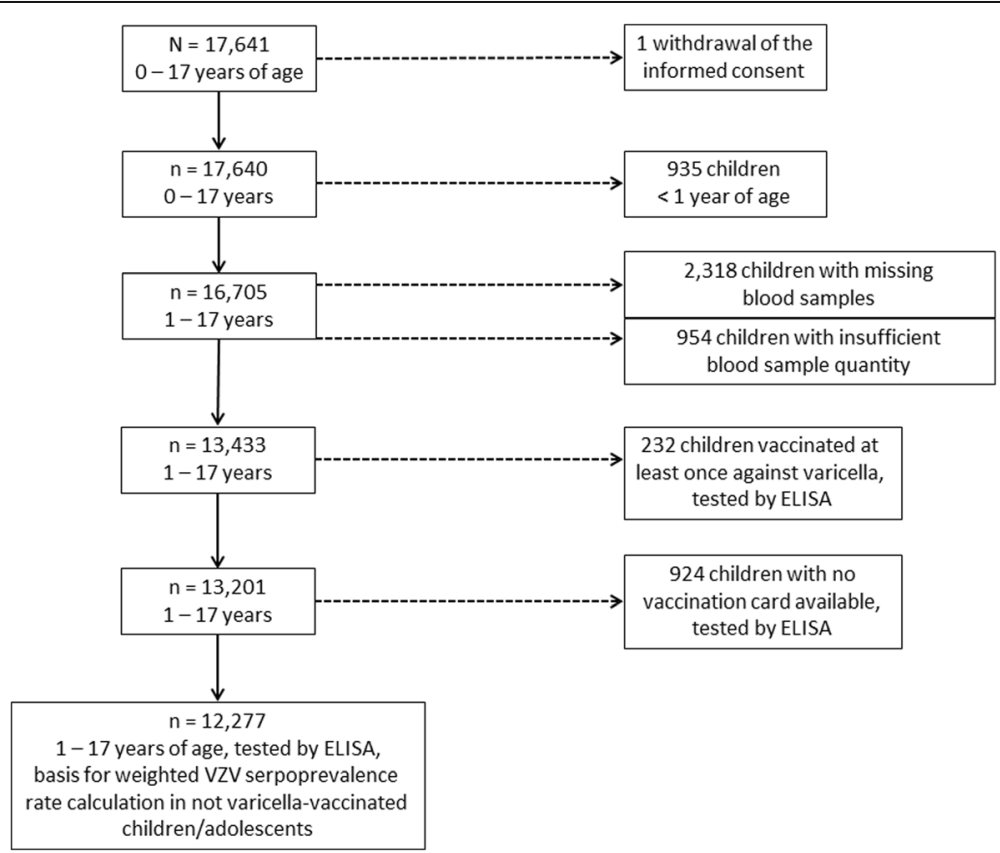

Fig. 1 Flow chart indicating the total number of children in the study sample (sera collected 2003-2006, N=17,641) and number of children eventually tested for anti-VZV IgG antibodies by ELISA 
Table 1 Weighted VZV seroprevalence data tested by ELISA and stratified by varicella vaccination status in children 1-17 years of age, Germany (sera collected 2003-2006, $n=13,433$ )

\begin{tabular}{|c|c|c|c|c|c|}
\hline \multirow{2}{*}{$\begin{array}{l}\text { Anti-VZV IgG } \\
\text { antibodies } \\
\text { tested by ELISA }\end{array}$} & & \multicolumn{3}{|l|}{ Varicella vaccination status } & \multirow[t]{2}{*}{ Total } \\
\hline & & No vaccination card available & Varicella vaccinated & Not varicella vaccinated & \\
\hline \multirow[t]{3}{*}{ Positive } & number $(n)$ & 811 & 124 & 10,156 & 11,091 \\
\hline & weighted rate (\%) & $87.7 \%$ & $48.9 \%$ & $80.3 \%$ & $80.3 \%$ \\
\hline & $95 \% \mathrm{Cl}[\%]$ & {$[84.8-90.1]$} & {$[40.2-57.8]$} & {$[79.3-81.3]$} & {$[79.4-81.2]$} \\
\hline \multirow[t]{3}{*}{ Negative } & number $(n)$ & 109 & 90 & 2023 & 2222 \\
\hline & weighted rate (\%) & $12.0 \%$ & $41.4 \%$ & $18.9 \%$ & $18.8 \%$ \\
\hline & $95 \%$ Cl [\%] & {$[9.7-14.8]$} & {$[34.4-48.8]$} & [18.0-19.9] & [17.9-19.8] \\
\hline \multirow[t]{3}{*}{ Equivocal result } & number $(n)$ & 4 & 18 & 98 & 120 \\
\hline & weighted rate (\%) & $0.3 \%$ & $9.6 \%$ & $0.7 \%$ & $0.9 \%$ \\
\hline & $95 \% \mathrm{Cl}[\%]$ & {$[0.1-1.0]$} & {$[5.7-15.9]$} & {$[0.6-0.9]$} & {$[0.7-1.1]$} \\
\hline \multirow[t]{2}{*}{ Total } & number $(n)$ & 924 & 232 & 12,277 & 13,433 \\
\hline & weighted rate (\%) & $100.0 \%$ & $100.0 \%$ & $100.0 \%$ & $100.0 \%$ \\
\hline
\end{tabular}

this study, 935 of the children were $<1$ year of age and blood sampling was not performed in this age group, 2318 of the children had no available serum sample, and 954 of the children had a serum samples of insufficient quantity (Fig. 1). Gender was distributed evenly in the study population with 6881 (51\%) males and 6552 (49\%) females. Each age group (1 to 17 years), had 437 to 938 participants included. The mean age of all study participants was 10.1 years (median age: 10.3 years). Of the 13,433 children included, $232(1.7 \%)$ had a vaccination card with at least one vaccination against varicella documented, while $924(6.9 \%)$ children had no vaccination card available. In Table 1, the weighted VZV seroprevalence data are shown stratified by varicella vaccination status. Of the 13,433 sera tested by ELISA, 11,091 (estimated weighted overall VZV seroprevalence rate: 80.3\%) samples were classified as positive, $120(0.9 \%)$ samples presented an equivocal result, and 2222 (18.8\%) samples were found to be negative for anti-VZV IgG (Table 1). Varicella-vaccinated children and children with no vaccination card available were excluded from further analyses that focused on the seroprevalence and risk of being varicella susceptible in the varicella-unvaccinated population. In Table 2, weighted VZV seropositivity rates detected by ELISA are given for each age group in varicella-unvaccinated children. While VZV seropositivity increased with age with significant differences between single age groups up to the age of 6 years, no

Table 2 Weighted VZV seroprevalence rates stratified by age in varicella-unvaccinated children 1-17 years of age, Germany

\begin{tabular}{|c|c|c|c|c|c|c|c|c|c|}
\hline \multirow{2}{*}{$\begin{array}{l}\text { Anti-VZV IgG antibodies tested by ELISA, } \\
\text { weighted seroprevalence rate }[\%(95 \% \mathrm{CI})]\end{array}$} & \multicolumn{9}{|c|}{ Age in years } \\
\hline & $\begin{array}{l}1 \\
(n=374)\end{array}$ & $\begin{array}{l}2 \\
(n=503)\end{array}$ & $\begin{array}{l}3 \\
(n=569)\end{array}$ & $\begin{array}{l}4 \\
(n=644)\end{array}$ & $\begin{array}{l}5 \\
(n=662)\end{array}$ & $\begin{array}{l}6 \\
(n=765)\end{array}$ & $\begin{array}{l}7 \\
(n=800)\end{array}$ & $\begin{array}{l}8 \\
(n=832)\end{array}$ & $\begin{array}{l}9 \\
(n=839)\end{array}$ \\
\hline Positive & $\begin{array}{l}12.0 \\
(8.1-17.4)\end{array}$ & $\begin{array}{l}25.2 \\
(20.8-30.1)\end{array}$ & $\begin{array}{l}38.4 \\
(33.5-43.5)\end{array}$ & $\begin{array}{l}60.1 \\
(55.6-64.4)\end{array}$ & $\begin{array}{l}73.3 \\
(68.9-77.2)\end{array}$ & $\begin{array}{l}85.7 \\
(82.4-88.5)\end{array}$ & $\begin{array}{l}87.3 \\
(84.4-89.8)\end{array}$ & $\begin{array}{l}89.6 \\
(87.2-91.6)\end{array}$ & $\begin{array}{l}93.2 \\
(90.5-95.1)\end{array}$ \\
\hline Negative & $\begin{array}{l}87.8 \\
(82.4-91.7)\end{array}$ & $\begin{array}{l}74.4(69.5- \\
78.8)\end{array}$ & $\begin{array}{l}60.9(55.8- \\
65.7)\end{array}$ & $\begin{array}{l}39.4(35.1- \\
43.9)\end{array}$ & $\begin{array}{l}26.2(22.3- \\
30.6)\end{array}$ & $\begin{array}{l}14.0(11.2- \\
17.3)\end{array}$ & $\begin{array}{l}12.0 \\
(9.6-14.9)\end{array}$ & $\begin{array}{l}9.4 \\
(7.5-11.7)\end{array}$ & $\begin{array}{l}6.0 \\
(4.2-8.6)\end{array}$ \\
\hline Equivocal result & $\begin{array}{l}0.2 \\
(0.0-1.5)\end{array}$ & $\begin{array}{l}0.4 \\
(0.1-1.5)\end{array}$ & $\begin{array}{l}0.7 \\
(0.2-2.8)\end{array}$ & $\begin{array}{l}0.5 \\
(0.2-1.5)\end{array}$ & $\begin{array}{l}0.5 \\
(0.2-1.4)\end{array}$ & $\begin{array}{l}0.3 \\
(0.1-0.8)\end{array}$ & $\begin{array}{l}0.6 \\
(0.3-1.6)\end{array}$ & $\begin{array}{l}1.0 \\
(0.5-2.0)\end{array}$ & $\begin{array}{l}0.8 \\
(0.4-1.7)\end{array}$ \\
\hline \multirow{2}{*}{$\begin{array}{l}\text { Anti-VZV IgG antibodies tested by ELISA, } \\
\text { weighted seroprevalence rate }[\%(95 \% \mathrm{CI})]\end{array}$} & \multicolumn{9}{|l|}{ Age in years } \\
\hline & $\begin{array}{l}10 \\
(n=808)\end{array}$ & $\begin{array}{l}11 \\
(n=861)\end{array}$ & $\begin{array}{l}12 \\
(n=808)\end{array}$ & $\begin{array}{l}13 \\
(n=830)\end{array}$ & $\begin{array}{l}14 \\
(n=814)\end{array}$ & $\begin{array}{l}15 \\
(n=794)\end{array}$ & $\begin{array}{l}16 \\
(n=712)\end{array}$ & $\begin{array}{l}17 \\
(n=662)\end{array}$ & $\begin{array}{l}\text { Total } \\
(n=12,277)\end{array}$ \\
\hline Positive & $\begin{array}{l}94.1 \\
(91.7-95.9)\end{array}$ & $\begin{array}{l}93.0 \\
(90.5-94.9)\end{array}$ & $\begin{array}{l}93.7 \\
(91.4-95.5)\end{array}$ & $\begin{array}{l}94.0 \\
(91.6-95.7)\end{array}$ & $\begin{array}{l}94.5 \\
(92.6-96.0)\end{array}$ & $\begin{array}{l}95.4 \\
(93.5-96.8)\end{array}$ & $\begin{array}{l}96.4 \\
(94.6-97.6)\end{array}$ & $\begin{array}{l}94.2 \\
(91.8-96.0)\end{array}$ & $\begin{array}{l}80.3 \\
(79.3-81.3)\end{array}$ \\
\hline Negative & $\begin{array}{l}5.4 \\
(3.8-7.7)\end{array}$ & $\begin{array}{l}6.6 \\
(4.8-9.0)\end{array}$ & $\begin{array}{l}5.0 \\
(3.5-7.1)\end{array}$ & $\begin{array}{l}5.0 \\
(3.5-7.2)\end{array}$ & $\begin{array}{l}4.5 \\
(3.2-6.3)\end{array}$ & $\begin{array}{l}3.7 \\
(2.5-5.5)\end{array}$ & $\begin{array}{l}3.3 \\
(2.1-5.0)\end{array}$ & $\begin{array}{l}4.3 \\
(2.8-6.6)\end{array}$ & $\begin{array}{l}18.9 \\
(18.0-19.9)\end{array}$ \\
\hline Equivocal result & $\begin{array}{l}0.5 \\
(0.2-1.2)\end{array}$ & $\begin{array}{l}0.4 \\
(0.1-1.0)\end{array}$ & $\begin{array}{l}1.3 \\
(0.7-2.5)\end{array}$ & $\begin{array}{l}1.0 \\
(0.5-2.3)\end{array}$ & $\begin{array}{l}1.0 \\
(0.5-1.9)\end{array}$ & $\begin{array}{l}0.8 \\
(0.4-1.9)\end{array}$ & $\begin{array}{l}0.4 \\
(0.1-1.2)\end{array}$ & $\begin{array}{l}1.5 \\
(0.7-2.9)\end{array}$ & $\begin{array}{l}0.7 \\
(0.6-0.9)\end{array}$ \\
\hline
\end{tabular}




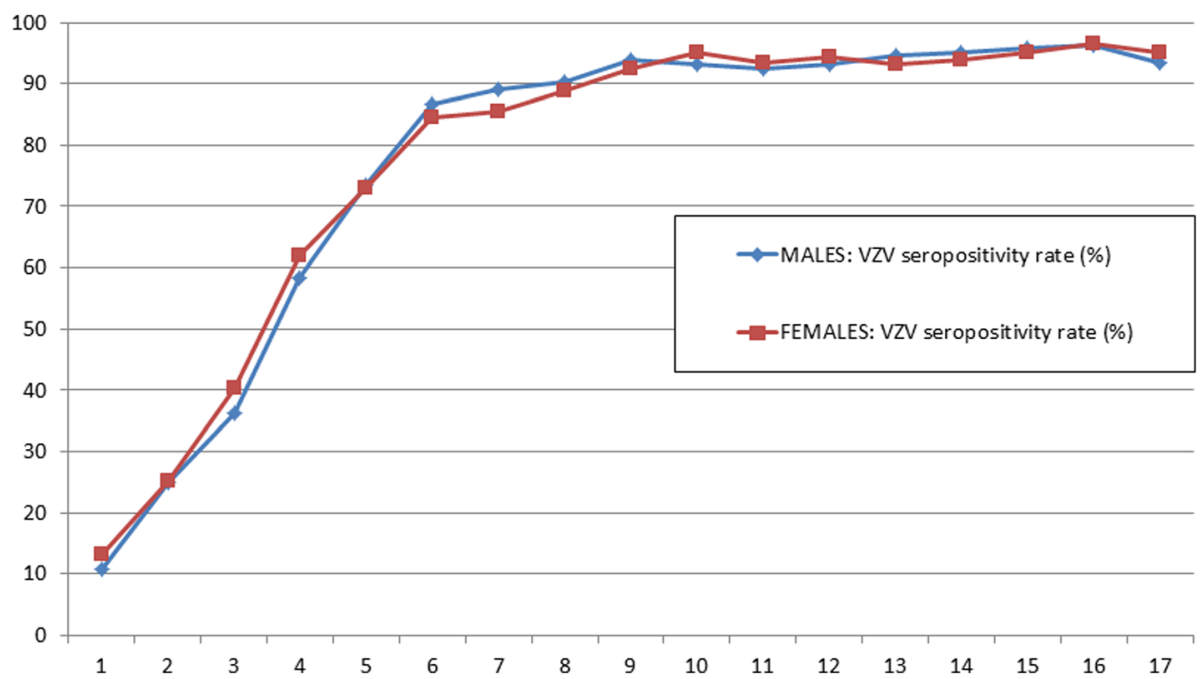

Fig. 2 Weighted VZV seropositivity rate stratified by age and sex in varicella-unvaccinated children 1-17 years of age, Germany (sera collected $2003-2006, n=12,277)$

significant difference in VZV seropositivity was detected between males and females (Fig. 2).

Of the 2222 serum samples that tested negative for anti-VZV IgG by ELISA, 919 samples of children aged 1-6 years and 535 samples of children aged 7-17 years were subsequently examined by FAMA. This test found $24(2.6 \%)$ samples in the age group of $1-6$ years and 48 (9.0\%) samples in the age group of 7-17 years to be positive. Additionally, 118 of the 120 serum samples that presented an equivocal result by ELISA were tested by FAMA. Of these, 54 (45.8\%) samples were assessed as positive by this test. Of the 197 serum samples taht demonstrated a positive ELISA result, 195 (99\%) were also FAMA-positive, while only 2 (1\%) samples were assessed as negative by FAMA (Fig. 3). In Table 3, we present stratified ELISA and FAMA results by varicella

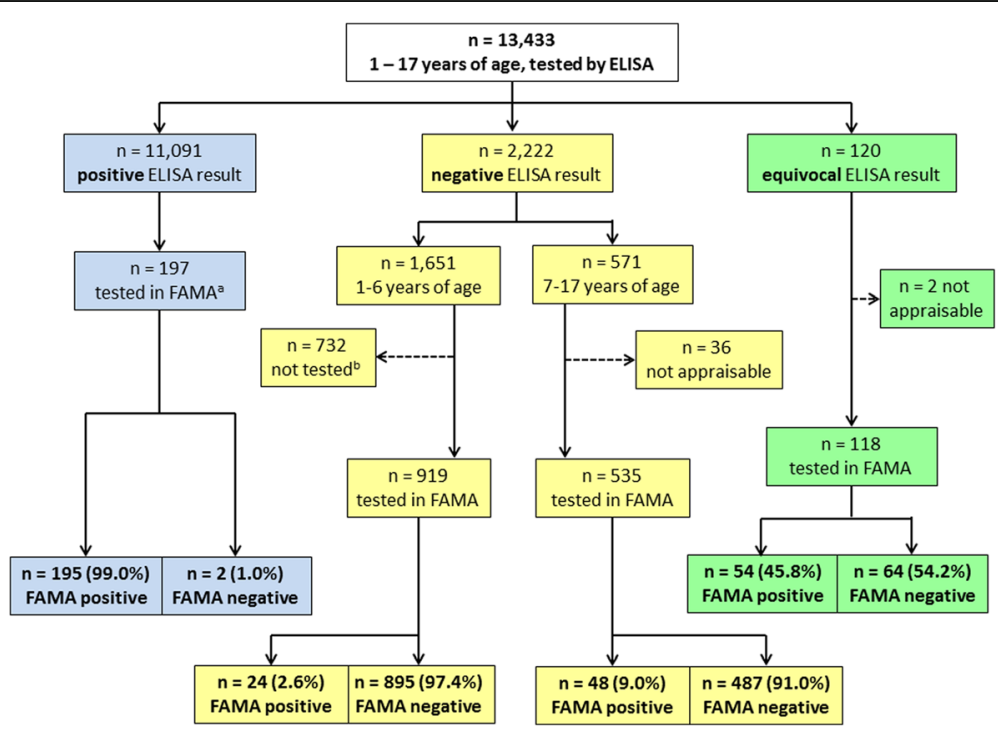

a Random selection of 100 participants age group 1-6 years and 100 of age group 7-17

years, 3 missing blood samples in age group 1-6 years.

b Of the 1,651 participants of age group 1-6 years who were tested negative by ELISA,

919 participants were selected randomly for the FAMA-testing.

Fig. 3 Flow chart of study subjects for VZV seroprevalence testing by FAMA in children 1-17 years of age, Germany (sera collected 2003-2006, $n=13,433$ ) 
Table 3 Results of ELISA and FAMA for the detection of anti-VZV lgG antibodies in sera of children $1-17$ years of age $(n=1769$ tested by ELISA and FAMA). The data set was stratified by the varicella vaccination status of the children. Germany

\begin{tabular}{|c|c|c|c|}
\hline \multicolumn{4}{|l|}{ ELISA positive } \\
\hline & \multicolumn{3}{|l|}{ FAMA } \\
\hline & positive $n(\%)$ & negative $n(\%)$ & total $n(\%)$ \\
\hline varicella vaccinated & $5(100 \%)$ & 0 & $5(100 \%)$ \\
\hline not varicella vaccinated & 176 (99\%) & $2(1 \%)$ & 178 (100\%) \\
\hline no vaccination card & $14(100 \%)$ & 0 & $14(100 \%)$ \\
\hline total & 195 (99\%) & $2(1 \%)$ & $197(100 \%)$ \\
\hline \multicolumn{4}{|l|}{ ELISA negative } \\
\hline & \multicolumn{3}{|l|}{ FAMA } \\
\hline & positive $n(\%)$ & negative $n(\%)$ & total $n(\%)$ \\
\hline varicella vaccinated & $12(25.5 \%)$ & $35(74.5 \%)$ & 47 (100\%) \\
\hline not varicella vaccinated & $53(4.0 \%)$ & $1268(96.0 \%)$ & $1321(100 \%)$ \\
\hline no vaccination card & $7(8.1 \%)$ & 79 (91.9\%) & $86(100 \%)$ \\
\hline total & $72(5.0 \%)$ & $1382(95.0 \%)$ & $1454(100 \%)$ \\
\hline \multicolumn{4}{|l|}{ ELISA equivocal result } \\
\hline & \multicolumn{3}{|l|}{ FAMA } \\
\hline & positive $n(\%)$ & negative $n(\%)$ & total $n(\%)$ \\
\hline varicella vaccinated & $12(66.7 \%)$ & $6(33.3 \%)$ & $18(100 \%)$ \\
\hline not varicella vaccinated & $39(40.6 \%)$ & $57(59.4 \%)$ & $96(100 \%)$ \\
\hline no vaccination card & $3(75.0 \%)$ & $1(25.0 \%)$ & $4(100 \%)$ \\
\hline total & $54(45.8 \%)$ & $64(54.2 \%)$ & $118(100 \%)$ \\
\hline
\end{tabular}

vaccination status. Serum samples from varicellavaccinated children that had produced either negative or equivocal ELISA results were more frequently assessed as positive by FAMA than were serum samples from varicella-unvaccinated children.

In a logistic regression for complex samples, we did not observe any significant association between VZV seropositivity and either the socioeconomic status or the sex of the child. In children who were 1-10 years of age, increasing age was significantly associated with the acquisition of anti-VZV IgG antibodies. In 1- to 6-year-old children, the presence of older siblings in the same household was related to a higher probability of VZV seropositivity, and in children 7-17 years of age, younger siblings or siblings of the same age functioned as risk factor for VZV seropositivity. Thus, children without siblings in the same household were more likely to be antiVZV IgG-negative and, therefore, susceptible to contracting chickenpox. Children aged 7-17 years whose parents both had a migration background showed a significantly lower likelihood of VZV seropositivity than children without a migration background or with a onesided migration background. The start of day-care attendance at younger ages was also significantly associated with VZV seropositivity (Table 4).

\section{Discussion}

Here, we report for the first time representative population-based VZV seroprevalence data for children aged 1 to 17 years in the pre-varicella vaccine era in Germany. VZV seropositivity increased with age, with $60 \%$ of children testing positive at 4 years of age and $>90 \%$ testing positive at 9 years of age. This gradual increase in VZV seropositivity by age is comparable with the VZV seroprevalence data of German children $<18$ years of age that were reported by Wutzler et al. in 2001 [13]. For this earlier seroprevalence study, two serum banks were used with residual serum samples that had originally been collected for routine laboratory diagnostics or within the German National Health Interview and Examination Survey between 1995 and 1999. They found that VZV seropositivity was $62 \%$ in the 4 - to 5 -year old children and $>90 \%$ in the 10 - to 11 year old children. Thus, the seroprevalence data of the 1995-1999 study are similar to ours, and we can assume that there was no significant change in the VZV seroprevalence in children in Germany for the time period between 1995 and 1999 and 2003-2006. Also similar to our results, the majority of varicella infection occurred in early childhood in Northern European countries without universal varicella vaccination [16]. Interestingly, children in the Netherlands acquired antiVZV IgG antibodies, on average, even earlier in childhood than did children in Germany or in Nordic countries, and some have proposed that the relatively high population density in the Netherlands might explain this observation [17]. There are contradicting reports from the Netherlands concerning whether or not VZV seropositivity is associated with day-care attendance $[17,18]$. In our study, we found an association between VZV seropositivity and an early ( $<3$ years of age) start of day care attendance. However, this finding may be explained by the low rate of young children (0-3 years of age) who attend day care facilities at all in Germany. In 2006, around 12\% of children who were $<3$ years of age visited a day care center in Germany [19]; in contrast, around 50\% of children in the Netherlands who were $<3$ years of age attended day care facilities in 2010 [20]. Since we can assume that in the absence of varicella vaccination the force of varicella infection was high in day care facilities, we were able to discriminate in regard to VZV seropositivity between children with an early start of day care attendance and children who stayed at home. Additionally, we showed that siblings living in the same household acted as a risk factor for acquiring varicella: for young children, older siblings in the same household were a risk factor for VZV seropositivity, and, for older children, their younger 
Table 4 Results of the logistic regression model with VZV seropositivity as the dependent variable; data set stratified in three age groups: children 1 to 6 years of age, 7 to 10, and 11 to 17 years of age. Variables with statistically significant results presented here. Germany (sera collected 2003-2006, available for logistic regression model $n=11,374$ )

\begin{tabular}{|c|c|c|c|c|c|c|}
\hline \multirow[b]{3}{*}{ Variable } & \multicolumn{2}{|c|}{ Age 1 to 6 years } & \multicolumn{2}{|c|}{ Age 7 to 10 years } & \multicolumn{2}{|c|}{ Age 11 to 17 years } \\
\hline & \multicolumn{2}{|l|}{$n=3162$} & \multicolumn{2}{|l|}{$n=3058$} & \multicolumn{2}{|l|}{$n=5154$} \\
\hline & OR & $95 \% \mathrm{Cl}$ & OR & $95 \% \mathrm{Cl}$ & OR & $95 \% \mathrm{Cl}$ \\
\hline Age 1 year & Referent & & & & & \\
\hline 2 years & 2.2 & $1.4-3.7$ & & & & \\
\hline 3 years & 4.1 & $2.5-6.9$ & & & & \\
\hline 4 years & 11.0 & $6.6-18.3$ & & & & \\
\hline 5 years & 21.7 & $12.8-37.1$ & & & & \\
\hline 6 years & 51.0 & $30.6-85.3$ & & & & \\
\hline 7 years & & & Referent & & & \\
\hline 8 years & & & 1.4 & $1.0-1.9$ & & \\
\hline 9 years & & & 2.0 & $1.3-3.1$ & & \\
\hline 10 years & & & 2.5 & $1.6-4.1$ & & \\
\hline \multicolumn{7}{|l|}{ Siblings living in the same household: } \\
\hline only child & Referent & Referent & Referent & Referent & Referent & Referent \\
\hline younger or same age of the siblings & 1.1 & $0.9-1.5$ & 1.7 & $1.1-2.6$ & 1.7 & $1.2-2.4$ \\
\hline older siblings & 2.3 & $1.9-2.9$ & 1.3 & $0.9-1.8$ & 1.2 & $0.8-1.8$ \\
\hline \multicolumn{7}{|l|}{$\begin{array}{l}\text { Age at start of day-care attendance } \\
\text { ( } 1 \text { to } 10 \text { year olds) }\end{array}$} \\
\hline$<1$ year & 1.6 & $1.0-2.5$ & 1.8 & $0.7-4.2$ & & \\
\hline 1 year & 1.6 & $1.1-2.2$ & 2.0 & $1.1-3.5$ & & \\
\hline 2 years & 1.3 & $0.9-1.8$ & 4.1 & $2.2-7.7$ & & \\
\hline$>=3$ years & 0.9 & $0.7-1.2$ & 1.7 & $1.2-2.4$ & & \\
\hline \multicolumn{7}{|l|}{ Migration background: } \\
\hline none & 1.3 & $0.9-1.7$ & 1.5 & $1.0-2.3$ & 1.6 & $1.0-2.5$ \\
\hline one-sided & 1.1 & $0.7-1.7$ & 1.3 & $0.6-2.5$ & 1.5 & $0.8-3.0$ \\
\hline two-sided & Referent & & Referent & & Referent & \\
\hline
\end{tabular}

siblings played this role. Thus, in the absence of universal varicella vaccination in children, our data confirm that children are the major force of varicella infection.

There are concerns about an upward shift in varicella infection age following the introduction of universal varicella vaccination in young children [21]. Our study adds to the efforts of monitoring the impact of varicella vaccination in Germany, in part to address these concerns. Despite these worries, this phenomenon has not been observed in varicella surveillance in Germany, which is a physician-based sentinel system established in 2005 shortly after the initiation of universal childhood varicella vaccination [22]. Similarly, in the United States, where universal varicella vaccination in children was implemented in 1995, no shift in varicella cases towards older age groups has been observed as of today [23]. This present serosurvey will serve as a baseline assessment, and a follow-up survey (KiGGS wave 2) which will allow a comparison between more recent results and those of this present study, is currently underway and will recruit children from 2014 to 2017.

In our survey, we detected subgroups within the general population that have an increased risk of being susceptible to varicella infection if they are not reached by an ad-hoc catch-up vaccination; children 7-17 years of age with a migration background and children without siblings were less likely to be anti-VZV IgG-positive. Since no concerted catch-up campaign has been implemented among older children or adolescents following the introduction of universal childhood vaccination in toddlers, pediatricians and general practitioners should be aware of this fact and provide individual varicella catch-up vaccinations to these risk groups if an individual lacks a history of chickenpox and has no documented varicella vaccination. STIKO recommends 
individual catch-up vaccination to all children up to their 18th birthday and to all VZV-seronegative women of childbearing age.

We compared the detection of anti-VZV IgG by a commercially available ELISA with that by an in-house FAMA, which can be regarded as the gold standard [24]. We observed that $45.8 \%$ of samples with equivocal ELISA results were assessed as positive by FAMA. Additionally, $2.6 \%$ and $9.0 \%$, respectively (depending on the age of the tested children), of ELISA-negative serum samples were determined to be positive by FAMA. As the gold standard assay, FAMA has a higher sensitivity and a lower detection limit than an ELISA [25]. The EUROIMMUN Anti-VZV (IgG) ELISA was reported to have a significantly lower sensitivity than FAMA, especially for the detection of anti-VZV IgG after varicella vaccination has been performed [14]. Interestingly, when serum samples that produced a negative or equivocal ELISA result were tested by FAMA, we more often observed a positive FAMA result in samples from varicella-vaccinated children than in samples from varicella-unvaccinated ones (Table 3). Although there was only a small number of varicellavaccinated children in the study sample, our findings might be important for the monitoring of VZV seroprevalence in a varicella-vaccinated population. Because it is possible that anti-VZV IgG levels in varicellavaccinated populations are overall lower, which would lead to a higher frequency of equivocal or even negative ELISA results, retesting these sera by FAMA might become much more relevant. Unfortunately, FAMA is a labor-intensive and time-consuming method that is not amenable to automation and requires experience for an appropriate interpretation of its results. Currently, FAMA tests are only performed in laboratories that are highly specialized in VZV diagnostics and research, and they are not commercially available. Therefore, it will be difficult to conduct FAMA for the detection of antiVZV IgG on a routine basis.

Our study has several limitations. For the weighted seroprevalence rate calculation for varicella-unvaccinated children 1-17 years of age, we excluded 1156 study subjects with at least one reported varicella vaccination or with no vaccination card presented. Furthermore, most of the information on migration status, family members, and SES were self-reported or reported by the parents. However, this limitation would only influence the results of the risk factor analysis, not the VZV seroprevalence data.

\section{Conclusion}

In our study, we determined the age-specific VZV seroprevalence among children and adolescents in the prevaricella vaccine era in Germany. We confirmed that, in the absence of universal varicella vaccination, VZV seropositivity increased with age, especially in the first 6 years of life, which suggests that the major force of varicella transmission occurred in young children. We identified children without siblings in the same household and children with a migration background as being more susceptible to contracting varicella, even at higher ages (7-17 years old). Therefore, varicella-unvaccinated children or adolescents should be targeted for catch-up activities if they lack a history of chickenpox.

We also compared the test qualities of a commercially available ELISA with those of a gold standard test (FAMA). A high number of serum samples with a negative or equivocal result in the ELISA produced a positive FAMA result, especially those from varicella-vaccinated children. Our findings suggest that the commercially available ELISA can be used for the monitoring the VZV seroepidemiology in populations with or without an established universal varicella vaccination, but that FAMA testing is superior in situations with equivocal ELISA results or in ELISA-negative samples from individuals who were vaccinated against varicella in the past. This study provides baseline data on VZV seroepidemiology in children and adolescents for monitoring the impact of the recently implemented varicella vaccination strategy in Germany. Moreover, these data act as input for mathematical modelling of the varicella and herpes zoster-attributable disease burden and of future epidemiological effects of the varicella-vaccination [26].

\section{Abbreviations \\ Cl: Confidence interval; ELISA: Enzyme-linked immunosorbent assay; FAMA: Fluorescent antibody to membrane antigen test; HSV: Herpes simplex virus; KiGGS: German Health Interview and Examination Survey for Children and Adolescents; OR: Odds ratio; SES: Social economic status; STIKO: German Standing Committee on Vaccination; VZV: Varicella-zoster virus}

\section{Acknowledgements}

The authors would like to thank Christine Schwerdtfeger and Kristin Döhring for their excellent work in conducting the ELISA- and FAMA-testing, respectively.

\section{Funding}

The KiGGS study was funded by the German Ministry of Health, the German Ministry of Education and Research, and the Robert Koch Institute (Berlin, Germany). Laboratory testing for anti-VZV IgG antibodies by ELISA and FAMA was funded by the Robert Koch Institute (Berlin, Germany).

\section{Availability of data and materials}

Data of the KiGGS study are available from: http://www.kiggs-studie.de/ deutsch/ergebnisse/kiggs-basiserhebung/public-use-file.html.The Department of Epidemiology and Health Reporting, Robert Koch Institute is holding the public use file. Applications to use this file must be sent to them.

\section{Authors' contributions}

All authors were involved in the conception and design of the study and interpretation of the results. MWP was responsible for conducting the study, literature search, and drafting of the article. Moreover she was involved in data analysis. AM was responsible for performing the ELISA testing. ASa was responsible for performing the FAMA testing. CPM was responsible for data analysis. All authors made substantial contribution to the conception and design of the article and interpreted the data critically. All authors revised the manuscript critically and contributed to the final draft. All authors read and approved the final manuscript. 


\section{Competing interests}

The authors declare that they have no competing interests.

\section{Consent for publication}

Not applicable.

\section{Ethics approval and consent to participate}

The KiGGS-survey was approved by the Federal Office for Data Protection and by the ethics committee of Charité University Medicine, Berlin, Germany. Parents of the participants and additionally adolescents of 14-17 years of age signed the written informed consent to the KiGGS study and the laboratory testing of their blood samples.

\section{Publisher's Note}

Springer Nature remains neutral with regard to jurisdictional claims in published maps and institutional affiliations.

\section{Author details}

'Department for Infectious Disease Epidemiology, Robert Koch Institute, Immunization Unit, Seestrasse 10, 13353 Berlin, Germany. ${ }^{2}$ Department of Infectious Diseases, Robert Koch Institute, Berlin, Germany. ${ }^{3}$ Institute of Virology and Antiviral Therapy, German Consulting Laboratory for HSV and VZV, Jena University Hospital, Friedrich-Schiller-University of Jena, Jena, Germany. ${ }^{4}$ Institute of Virology, Medical Center, Albrecht-Ludwigs-University, Faculty of Medicine, Freiburg, Germany. ${ }^{5}$ Department of Epidemiology and Health Monitoring, Robert Koch Institute, Berlin, Germany.

Received: 10 January 2017 Accepted: 11 May 2017 Published online: 19 May 2017

\section{References}

1. Heininger U, Seward JF. Varicella. Lancet. 2006:368(9544):1365-76.

2. Liese JG, Grote V, Rosenfeld E, Fischer R, Belohradsky BH, v Kries R, Group EVS The burden of varicella complications before the introduction of routine varicella vaccination in Germany. Pediatr Infect Dis J. 2008;27(2):119-24.

3. German-Standing-Committee-on-Vacccination. Empfehlungen der Ständigen Impfkommission (STIKO) am Robert Koch Institut/Stand: Juli 2004. Epidemiol Bull. 2004;30:235-50.

4. German-Standing-Committee-on-Vacccination. Empfehlungen der Ständigen Impfkommission (STIKO) am Robert Koch Institut/Stand: Juli 2009. Epidemiol Bull. 2009;30:279-98.

5. Siedler A, Hecht J, Rieck T, Tolksdorf K, Hengel H. Varicella vaccination in Germany. A provisional appraisal in the context of MMR vaccination. Bundesgesundheitsblatt, Gesundheitsforschung, Gesundheitsschutz. 2013; 56(9):1313-20.

6. German-Standing-Committee-on-Vacccination. Stellungnahme der Ständigen Impfkommission (STIKO): Evaluation der Varizellen-Impfempfehlung durch die STIKO. Epidemiol Bull. 2013;1:1-5

7. Spackova M, Muehlen M, Siedler A. Complications of varicella after implementation of routine childhood varicella vaccination in Germany. Pediatr Infect Dis J. 2010;29(9):884-6.

8. Siedler A, Rieck T, Tolksdorf K. Strong additional effect of a second Varicella vaccine dose in children in Germany, 2009-2014. J Pediatr. 2016;173:202-6. e202

9. Begg N, Miller E. Role of epidemiology in vaccine policy. Vaccine. 1990; 8(3):180-9.

10. Krah DL. Assays for antibodies to varicella-zoster virus. Infect Dis Clin N Am. 1996:10(3):507-27.

11. Kurth BM, Kamtsiuris $P$, Holling H, Schlaud M, Dolle R, Ellert U, Kahl H, Knopf $H$, Lange $M$, Mensink GB, et al. The challenge of comprehensively mapping children's health in a nation-wide health survey: design of the German KiGGS-study. BMC Public Health. 2008;8:196.

12. Euroimmun-Medizinische-Labordiagnostika: Anti-VZV-ELISA (lgG): product description. https://www.euroimmun.com/products/indications/infektionsserologie/immunittsbestimmung.html. 2016. Accessed 25 Aug 2016.

13. Wutzler P, Farber I, Wagenpfeil S, Bisanz H, Tischer A. Seroprevalence of varicella-zoster virus in the German population. Vaccine. 2001;20(1-2):121-4.

14. Sauerbrei A, Schafler A, Hofmann J, Schacke M, Gruhn B, Wutzler P. Evaluation of three commercial varicella-zoster virus lgG enzyme-linked immunosorbent assays in comparison to the fluorescent-antibody-to- membrane-antigen test. Clinical and vaccine immunology: CVI. 2012;19(8): 1261-8.

15. Lampert T, Kroll LE, Muters S, Stolzenberg H. Measurement of the socioeconomic status within the German health update 2009 (GEDA). Bundesgesundheitsblatt, Gesundheitsforschung, Gesundheitsschutz. 2013;56(1):131-43.

16. Nardone A, de Ory F, Carton M, Cohen D, van Damme P, Davidkin I, Rota MC, de Melker H, Mossong J, Slacikova M, et al. The comparative seroepidemiology of varicella zoster virus in 11 countries in the European region. Vaccine. 2007;25(45):7866-72.

17. de Melker $H$, Berbers $G$, Hahne $S$, Rumke $H$, van den Hof $S$, de Wit A, Boot $H$. The epidemiology of varicella and herpes zoster in The Netherlands: implications for varicella zoster virus vaccination. Vaccine. 2006;24(18):3946-52.

18. van Lier A, Smits G, Mollema L, Waaijenborg S, Berbers $G$, van der Klis F, Boot $\mathrm{H}$, Wallinga J, de Melker $\mathrm{H}$. Varicella zoster virus infection occurs at a relatively young age in The Netherlands. Vaccine. 2013;31(44):5127-33.

19. Statistisches-Bundesamt: Kinder in Tageseinrichtungen: Bundesländer, Stichtag, Altersgruppen. https://www-genesis.destatis.de/genesis/online/ data;jsessionid=3EA435F18B26C98679C70B0E75C53821.tomcat_GO_1_ 3?operation=abruftabellenVerzeichnis. Accessed 26 Aug 2016.

20. European-Commission: Use of childcare in the EU Member States and progress towards the Barcelona targets. http://eacea.ec.europa.eu/ education/eurydice/documents/key_data_series/166EN.pdf, Accessed 26 Aug 2016.

21. Papaloukas O, Giannouli G, Papaevangelou V. Successes and challenges in varicella vaccine. Ther Adv Vaccines. 2014;2(2):39-55.

22. Siedler A, Dettmann M. Hospitalization with varicella and shingles before and after introduction of childhood varicella vaccination in Germany. Human vaccines \& immunotherapeutics. 2014;10(12):3594-600.

23. Baxter R, Tran TN, Ray P, Lewis E, Fireman B, Black S, Shinefield HR, Coplan PM, Saddier P. Impact of vaccination on the epidemiology of varicella: 1995-2009. Pediatrics. 2014;134(1):24-30.

24. Plotkin SA. Correlates of protection induced by vaccination. Clinical and vaccine immunology : CVI. 2010;17(7):1055-65.

25. Saiman L, LaRussa P, Steinberg SP, Zhou J, Baron K, Whittier S, Della-Latta P, Gershon AA. Persistence of immunity to varicella-zoster virus after vaccination of healthcare workers. Infect Control Hosp Epidemiol. 2001;22(5):279-83.

26. Horn J, Karch A, Damm O, Kretzschmar ME, Siedler A, Ultsch B, Weidemann F, Wichmann O, Hengel H, Greiner W, et al. Current and future effects of varicella and herpes zoster vaccination in Germany - insights from a mathematical model in a country with universal varicella vaccination. Human vaccines \& immunotherapeutics. 2016;12(7):1766-76.

\section{Submit your next manuscript to BioMed Central and we will help you at every step:}

- We accept pre-submission inquiries

- Our selector tool helps you to find the most relevant journal

- We provide round the clock customer support

- Convenient online submission

- Thorough peer review

- Inclusion in PubMed and all major indexing services

- Maximum visibility for your research

Submit your manuscript at www.biomedcentral.com/submit
) Biomed Central 